- Original Article

\title{
Anti-fracture Efficacy of Monthly Risedronate Compared with That of Weekly Risedronate in Postmenopausal Korean Women with Osteoporosis: A Nationwide Cohort Study
}

\author{
Yong Ho Cho, Kyung Hyun Bae, Dong Ryul Lee*, Jungun Lee \\ Department of Family Medicine, Wonkwang University Sanbon Hospital, Wonkwang University School of Medicine, Gunpo, Korea
}

\begin{abstract}
Background: Intermittent dosing regimens for oral risedronate (once-monthly and once-weekly) were developed for patient convenience. While several studies have reported the anti-fracture efficacy of weekly dosing, few have assessed monthly dosing. The lower efficacy of monthly dosing has been previously suggested. The aim of this study was to compare the anti-fracture efficacy of monthly and weekly dosing.

Methods: We obtained information from the Korea National Health Insurance Service database from 2012 to 2017 of Korean women of $\geq 50$ years of age who used weekly or monthly risedronate. We compared the time of occurrence of the first osteoporotic fracture after the first prescription of risedronate. Using a Cox proportional model, we assessed incidence rate ratios (IRRs) with 95\% confidence intervals (CIs) for fractures at any site, and the hip, vertebral, and non-vertebral sites between both regimens. Propensity score weighting was used to balance the treatment groups.

Results: The study populations were distributed according to dosing frequency (monthly, 27,329; weekly, 47,652). There was no significant difference in the incidence rate of new fractures in any site (IRR, 1.008; 95\% CI, 0.9631.055; $\mathrm{P}=0.737$ ), hip (IRR, 0.999; 95\% CI, 0.769-1.298; $\mathrm{P}=0.996$ ), vertebral (IRR, 0.962; 95\% CI, 0.890-1.040; $\mathrm{P}=0.330$ ), or non-vertebral (1.022; 95\% CI, 0.968-1.078; $\mathrm{P}=0.439$ ) sites between monthly and weekly risedronate.

Conclusion: The anti-fracture efficacy at any site and the examined individual sites was similar for the monthly and weekly risedronate regimens. Large-scale randomized controlled trials are required for confirmation.
\end{abstract}

Keywords: Bisphosphonate; Risedronic Acid; Osteoporosis; Fracture

Received: July 31, 2019, Revised: November 19, 2019, Accepted: December 5, 2019

*Corresponding Author: Dong Ryul Lee https://orcid.org/0000-0001-7255-4561

Tel: +82-31-390-2965, Fax: +82-31-390-2266, E-mail: rednose7695@wku.ac.kr 


\section{INTRODUCTION}

Osteoporosis is one of the most common medical concerns observed in the elderly; it has emerged as a major health problem due to the aging population. ${ }^{1)}$ The 2008-2010 Korea National Health and Nutrition Examination Survey (KNHANES) reported that approximately $38.0 \%$ of Korean women of $\geq 50$ years of age were diagnosed with osteoporosis. ${ }^{2)}$ Korea is predicted to become an aging society (elderly population $\geq 14 \%$ of the total population) by 2018 and a super-aged society (elderly population $\geq 20 \%$ of the total population) by 2026 . ${ }^{3)}$ Accordingly, the prevalence of osteoporosis is predicted to escalate continuously.

An increase in fragility fractures, a major complication of osteoporosis, increases morbidity and mortality and decreases patient qualityof-life. Osteoporotic fractures increase mortality by approximately 1.8fold in postmenopausal women, who comprise a significant proportion of patients with osteoporosis. ${ }^{4)}$

The healthcare costs associated with osteoporosis in Korea increased annually from US dollar (USD) 3,976 million in 2007 to USD 5,126 million in 2011; these costs accounted for one-sixth (16.7\%) of the national healthcare expenditure and are expected to rise in future. ${ }^{5)}$ Therefore, osteoporosis and osteoporotic fractures are important public health problems in Korea as they have a major impact on qualityof-life, mortality, and economic burden.

Risedronate is a third-generation bisphosphonate that has emerged as a common treatment for osteoporosis in recent years. Different dosing regimens are used, including daily, weekly, and monthly regimens. Among these, a daily oral dose of $5 \mathrm{mg}$ was the first regimen approved after the anti-fracture efficacy was demonstrated. ${ }^{6,7)}$ Subsequently, the weekly (35 mg) and monthly (150 mg) dosing regimens were developed for patient convenience. Both regimens showed similar efficacy to that of the daily regimen with regard to bone mineral density (BMD) and bone turnover markers, ${ }^{8-11)}$ and were approved for clinical use. Less frequent dosing improves medication adherence. In addition, some of the side effects induced by the daily regimen were reduced, or at least similar, to those found in patients receiving the weekly and monthly regimens. ${ }^{8-14)}$

With regard to the fracture prevention effects, the efficacy of the weekly regimen has been proven through numerous randomized controlled trials (RCTs). ${ }^{11,13,15,16)}$ However, the efficacy of the monthly regimen has been evaluated in only a few studies. ${ }^{12,14,17)}$ Interestingly, among these studies, a recent large cohort study of Korean women with osteoporosis reported that a monthly risedronate group had more fracture events than a monthly ibandronate group. Given that the risk reduction of non-vertebral fracture has not been documented for ibandronate in contrast with risedronate, ${ }^{18)}$ this result was somewhat unexpected. However, current evidence is based mainly on "weekly" risedronate studies; hence, there is a need for studies comparing monthly and weekly risedronate. In a 2-year RCT, the monthly regimen showed a smaller decrease in serum type-1 collagen crossed linked C-telopeptide (CTX) levels than for the daily regimen after 1 year, although this change disappeared at 2 years. ${ }^{12)}$ This observation may suggest that monthly risedronate has, at least initially, a lower efficacy.

Thus, the aim of this study was to compare the effects of two risedronate regimens (monthly and weekly) on fracture prevention.

\section{METHODS}

\section{Data Source}

In South Korea, the government has implemented a compulsory National Health Insurance System that covers almost $100 \%$ of the Korean population. This study used data from the Korean National Health Insurance Service (KNHIS) collected between January 2012 and December 2017, inclusive. These data contained diagnoses, prescriptions, demographic information, and healthcare service use and outcomes. The KNHIS uses the diagnosis codes of the Korean Classification of Diseases, which is based on the International Classification of Disease, tenth revision (ICD-10).

New users of monthly or weekly risedronate were defined as those who were not prescribed any other bisphosphonates in the last 24 months. The first dispensing date of the study medication was defined as the study entry date. In the weekly risedronate group, we excluded those who received postprandial risedronate. We considered that all patients who received bisphosphonates were patients with osteoporosis because bisphosphonates may only be prescribed for osteoporosis in Korea.

The first sample cohort consisted of women of $\geq 50$ years of age, who used monthly or weekly risedronate. The second cohort was extracted from the first at a rate of approximately $50 \%$ because the National Health Insurance Sharing Service limits the cohort sampling to protect the sales information of the pharmaceutical companies. For the second sampling, we used stratified sampling by age (5-year intervals), region, and income.

Patients who used vitamin D during 180 days before entry into the study were excluded. In addition, patients diagnosed with a disease that could affect bone quality or the efficacy of bisphosphonates (osteomalacia, osteopetrosis, hypercalcemia, hyperparathyroidism, multiple myeloma, Paget disease, celiac disease, Cushing's syndrome, bone malignancy, renal impairment, or organ transplant) were excluded. If the patients in both treatment groups overlapped, those with an earlier study entry date were included. Patients who stopped treatment within the first 90 days were excluded because of the minimum duration required for a treatment effect.

\section{Ethics Statement}

The institutional review board of a regional hospital approved this study protocol (WMCSB 201806-46). The board waived the need for informed consent.

\section{Follow-up}

We followed the cohort for up to 4 years, until other bisphosphonates were prescribed, the patient died, low adherence to treatment was ob- 
served, a patient used vitamin $\mathrm{D}$ for more than 30 days within the study session, or the study session was terminated. The medication possession ratio (MPR) was used to measure treatment compliance. We defined the low adherence group as MPR $<80 \%$, based on a review analysis of adherence to osteoporosis treatments. ${ }^{19)}$ The MPR was obtained as the sum of the daily supply according to each bisphosphonate prescription over the total number of follow-up days.

\section{Covariates and Outcome}

Age and household income of the cohort were evaluated at baseline. Any clinical fracture that occurred during the 5 years before entry into the study in the vertebra, hip, pelvis, humerus, wrist, clavicle, lower leg, or ankle was defined as a history of fracture. We assessed medical service use (outpatient visits and/or hospitalizations), comorbidities, and recent medication within the 6 months before entry into the study. Health insurance service coverage provided for bisphosphonates was revised in October 2011, so we used the claim data extracted between January 2012 and December 2017, inclusive. Denosumab and teriparatide were not included in recent medications because no patients were prescribed these medications within 6 months before entry into the study. Corticosteroid use was defined as taking a dose equivalent to $450 \mathrm{mg}$ prednisone during the 6 months before entry into the study. The dose was calculated based on the guidelines of the American College of Rheumatology (5 mg prednisone for a minimum of 90 days). ${ }^{20)}$

The endpoint of the study was the first fracture event after entry into the study. An osteoporotic fracture, which can be caused by low-energy trauma, was defined based on following ICD-10 codes: fracture of the thoracic spine (S22.0 and S22.1); fracture of the lumbar spine (S32.0, S32.7, and 32.8); fracture of the ribs (S22.3 and S22.4); fracture of the pelvis (S32.1-32.5); fracture of the clavicle (S42.0); fracture of the humerus (S42.2-S42.4 and S42.7-S42.9), fracture of the forearm (S52), fracture of the wrist (S62.0-62.4 and S62.8), fracture of the femur (S72.0-S72.2 and S72.9); and fracture of the lower leg, including the ankle (S82).
We limited hip fracture to inpatients; other fractures were not limited to inpatients or outpatients. Patients with a fracture history during the 6 months before entry into the study were excluded, owing to the possibility of a follow-up visit after a recent fracture. We excluded the patients diagnosed with the following ICD-10 codes at the same time the event occurred: trauma injury (T05, T09, T11, T13, T14, T75, T79, V01-V99, W11-W17, W50-W52, W64, X34-X39, Y01-Y04, and Y30Y32), seizure (G40, G41, and R56), or pathologic fracture (M80, M84.4, and M90.7) during the study period.

\section{Statistical Analysis}

Inverse probability weighting was applied to balance the covariates between the treatment groups. The following variables that may have affected the risk of fracture were included: age, household income, history of fracture, medical service use, Charlson comorbidity index, comorbidities, and recent medication. The standardized difference was used to assess the balance between both treatment groups, and is considered as a small effect when it is less than 0.2. ${ }^{21)}$ Using the Cox proportional hazards model, we evaluated the difference in anti-fracture efficacy between both groups. We used graphical methods to evaluate the appropriation of the proportional hazards assumption. Kaplan-Meier curves were derived from both groups and we assessed the differences in the incidence of fracture between the groups by using the log-rank test. All statistical analyses were computed by using $\mathrm{R}$ statistical software ver. 3.5.2 (R Foundation for Statistical Computing, Vienna, Austria) and SAS ver. 9.4 (SAS Institute Inc., Cary, NC, USA). We considered a two-sided P-value of less than 0.05 to indicate statistical significance.

\section{RESULTS}

\section{Baseline Characteristics}

From the KNHIS database, we identified 790,956 Korean women of $\geq 50$ years of age who started monthly or weekly risedronate. Finally,

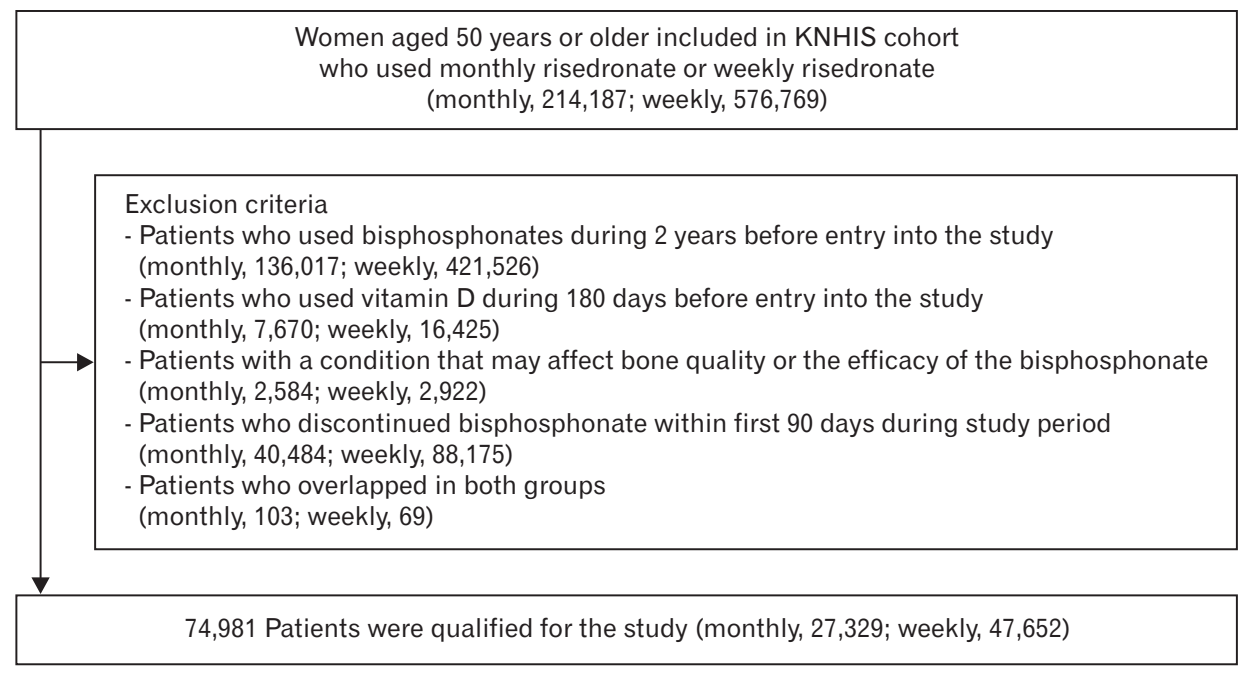

Figure 1. Flowchart for the selection of the study population. 
after exclusion in accordance with the specified criteria, 74,981 patients (monthly, 27,329; weekly, 47,652) were included in this study (Figure 1).

The baseline characteristics of the study populations before and after weighting are shown in Table 1. Patients from the weekly risedronate group were slightly younger than those in the monthly group. Other characteristics were similar between the groups. After the application of inverse probability weighting, the standard mean differences of all variables were $<0.2$ (maximum, 0.006).

We followed up the weekly group for a mean of $370.3 \pm 319.6$ days.
After the 1-year and 4-year follow-ups, $30.6 \%$ and $2.3 \%$ of patients who had been studied from baseline were left. The monthly group were followed up for a mean of $373.9 \pm 322.8$ days. After the 1-year and 4 -year follow-ups, $32.3 \%$ and $2.3 \%$ of the initial patient population remained. The proportion of follow-up patients decreased at each annual assessment owing to non-adherence to treatment.

\section{Risk of Fracture}

The number of new fractures, incidence rates per 1,000 person-years, and crude and adjusted IRRs of monthly risedronate compared with

Table 1. Baseline characteristics of the study population

\begin{tabular}{|c|c|c|c|c|}
\hline \multirow{2}{*}{ Characteristic } & \multirow{2}{*}{ Monthly risedronate $(\mathrm{n}=27,329)$} & \multirow{2}{*}{ Weekly risedronate $(n=47,652)$} & \multicolumn{2}{|c|}{ Standardized mean difference ${ }^{*}$} \\
\hline & & & Before & After \\
\hline Age (y) & $69.5 \pm 8.6$ & $67.6 \pm 8.8$ & 0.214 & 0.004 \\
\hline Household income level (deciles) & $6.4 \pm 3.0$ & $6.3 \pm 3.0$ & 0.053 & 0.003 \\
\hline \multicolumn{5}{|l|}{ History of fracture ${ }^{\dagger}$} \\
\hline Any site & $5,738(21.0)$ & $8,903(18.7)$ & 0.058 & 0.001 \\
\hline Hip & $318(1.2)$ & $490(1.0)$ & 0.013 & 0.003 \\
\hline Vertebral & 2,812 (10.3) & $4,072(8.6)$ & 0.060 & 0.003 \\
\hline Non-hip, non-vertebral & $3,406(12.5)$ & $5,320(11.2)$ & 0.040 & 0.005 \\
\hline Outpatient visit ${ }^{\ddagger}$ & $27,329(16.8)$ & $47,652(15.4)$ & 0.120 & $<0.001$ \\
\hline Hospitalization $^{\ddagger}$ & $5,682(20.8)$ & $9,513(20.0)$ & 0.021 & $<0.001$ \\
\hline Charlson comorbidity index ${ }^{\ddagger}$ & $2.09 \pm 2.1$ & $1.8 \pm 2.0$ & 0.120 & 0.001 \\
\hline \multicolumn{5}{|l|}{ Comorbidities $^{\ddagger}$} \\
\hline Dyslipidemia & $14,707(53.8)$ & $23,963(50.3)$ & 0.071 & $<0.001$ \\
\hline Hypertension & $15,221(55.7)$ & $23,476(49.3)$ & 0.129 & 0.005 \\
\hline Diabetes mellitus & 6,939 (25.4) & $10,325(21.7)$ & 0.088 & 0.005 \\
\hline Hyperthyroidism & $666(2.4)$ & $1,358(2.9)$ & 0.026 & 0.006 \\
\hline Rheumatoid arthritis & $2,153(7.9)$ & $3,868(8.1)$ & 0.009 & 0.006 \\
\hline \multicolumn{5}{|l|}{ Recent medication $n^{\ddagger}$} \\
\hline Corticosteroid & $447(1.6)$ & $765(1.6)$ & 0.002 & 0.001 \\
\hline Benzodiazepines & $10,245(37.4)$ & $15,523(32.6)$ & 0.103 & 0.005 \\
\hline Anticoagulants & $174(0.6)$ & $276(0.6)$ & 0.007 & 0.004 \\
\hline Antidepressants & $2,178(8.0)$ & $3,165(6.6)$ & 0.051 & 0.004 \\
\hline Proton pump inhibitors & $6,874(25.2)$ & $10,509(22.1)$ & 0.073 & 0.004 \\
\hline Estrogen & $345(1.3)$ & $773(1.6)$ & 0.030 & 0.004 \\
\hline Selective estrogen receptor modulators & 339 (1.2) & $459(1.0)$ & 0.027 & $<0.001$ \\
\hline Tibolone & $486(1.8)$ & $828(1.7)$ & 0.003 & 0.003 \\
\hline Thiazolidinediones & $395(1.5)$ & $560(1.2)$ & 0.024 & 0.003 \\
\hline
\end{tabular}

Values are presented as mean \pm standard deviation or number (\%), unless otherwise stated.

${ }^{*}$ Standardized mean difference, before and after inverse probability weighting. ${ }^{\dagger}$ Assessed in the 5 years before entry into the study. ${ }^{\star}$ Assessed in the 6 months before entry into the study.

Table 2. Number of events, incidence rates according to treatment group, and incidence rate ratio for monthly risedronate compared with the weekly risedronate for fracture for 4 years after inverse probability weighting

\begin{tabular}{|c|c|c|c|c|c|c|c|c|}
\hline \multirow[b]{2}{*}{ Type of fracture } & \multicolumn{2}{|c|}{ No. of new fracture } & \multicolumn{2}{|c|}{ Incidence rate* $(95 \% \mathrm{Cl})$} & \multicolumn{4}{|c|}{ Incidence rate ratio $(95 \% \mathrm{Cl})$} \\
\hline & $\begin{array}{l}\text { Monthly } \\
\text { risedronate }\end{array}$ & $\begin{array}{l}\text { Weekly } \\
\text { risedronate }\end{array}$ & $\begin{array}{l}\text { Monthly } \\
\text { risedronate }\end{array}$ & $\begin{array}{l}\text { Weekly } \\
\text { risedronate }\end{array}$ & Crude rate ratio ${ }^{\dagger}$ & P-value & Adjusted rate ratio ${ }^{\ddagger}$ & P-value \\
\hline Any site & 1,450 & 2,258 & $49.0(46.5-51.6)$ & $48.4(46.4-50.4)$ & $1.013(0.971-1.057)$ & 0.548 & 1.008 (0.963-1.055) & 0.737 \\
\hline Hip & 48 & 71 & $1.5(1.1-2.0)$ & $1.6(1.3-2.0)$ & $0.925(0.730-1.172)$ & 0.519 & 0.999 (0.769-1.298) & 0.996 \\
\hline Vertebral & 509 & 776 & $16.0(14.6-17.5)$ & $16.7(15.6-18.0)$ & $0.955(0.888-1.027)$ & 0.217 & $0.962(0.890-1.040)$ & 0.330 \\
\hline Non-vertebral ${ }^{\S}$ & 1,010 & 1,583 & $34.2(32.1-36.4)$ & $33.0(31.4-34.7)$ & $1.036(0.984-1.090)$ & 0.179 & $1.022(0.968-1.078)$ & 0.439 \\
\hline
\end{tabular}

$\mathrm{Cl}$, confidence interval.

${ }^{*}$ New fracture incidence per 1,000 person-years. 'Based on Cox proportional model. "Based on Cox proportional model, adjusted for patient's age, household income level, history of fracture, number of outpatient visit, hospitalization, Charlson comorbidity index, comorbidities, recent medication, and medication possession ratio. ${ }^{\S}$ Non-vertebral fracture contains hip, lower leg, forearm, wrist, humerus, clavicle, and rib fractures. 
weekly risedronate are shown in Table 2 . With regard to fractures at any site, the incidence rate of new fractures was similar in the monthly and weekly groups (49.0 and 34.2 per 1,000 person-years, respectively). The adjusted model showed no statistically significant difference between the monthly and weekly groups (IRR, 1.008; 95\% confidence interval [CI], 0.963-1.055; $\mathrm{P}=0.737$ ).

For the hip, vertebral, and non-vertebral fractures, the incidence rate of new fractures was similar between the monthly and weekly regimens (1.5, 1.6, and 48.4 in the monthly regimen, respectively; 16.0, 16.7 , and 33.0 in the weekly regimen, respectively). The differences in the incidence rates between the monthly and weekly groups were not statistically significant in the adjusted model (hip: IRR, 0.999; CI, 0.769-1.298; $\mathrm{P}=0.996$; vertebral: IRR, 0.962; CI, 0.890-1.040; $\mathrm{P}=0.330$; non-vertebral: IRR, 1.022; CI, 0.968-1.078; $\mathrm{P}=0.439$ ).

As shown by the Kaplan-Meier curves, the accumulated percentage of new fractures was significantly higher in the monthly group than in the weekly group in the unweighted curve during the follow-up (logrank test $\mathrm{P}=0.008$ ) (Figure 2). However, after weighting, there was no significant difference between the two groups (log-rank test $\mathrm{P}=0.699$ ). Collectively, the results showed that there were no statistically significant differences between the two groups in the incidence rate of fractures at any site and at each examined site.

\section{DISCUSSION}

This study was a retrospective, 4-year study that compared two risedronate dosing regimens: $150 \mathrm{mg}$ once per month versus $35 \mathrm{mg}$ once per week. The data showed that the monthly regimen of risedronate provided a similar anti-fracture efficacy to that of the weekly regimen at any site, or the hip, vertebral, and non-vertebral sites in Korean osteoporotic women of $\geq 50$ years of age.

Few studies have studied the anti-fracture efficacy of monthly risedronate. Notably, in a recent 4-year cohort study of Korean women with osteoporosis that compared monthly risedronate and monthly

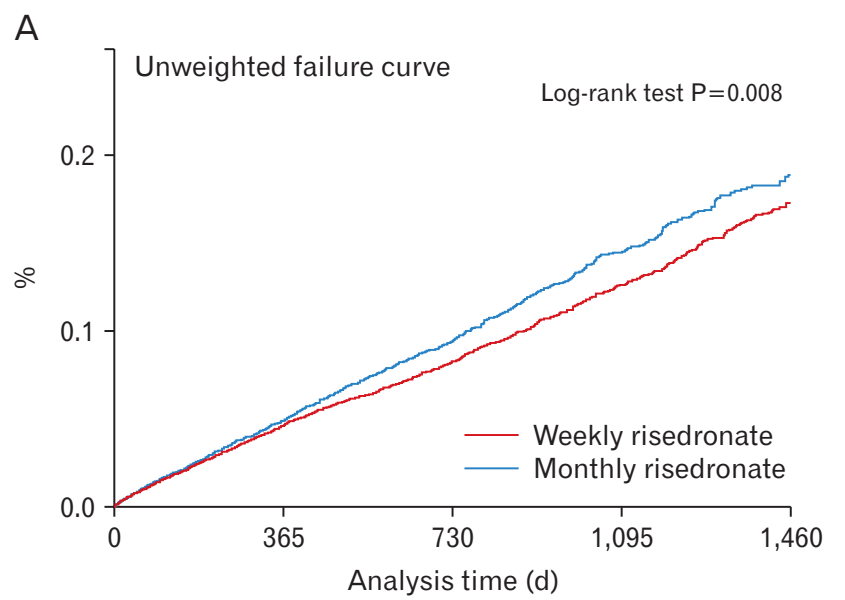

ibandronate, the anti-fracture efficacy of risedronate was found to be inferior to that of ibandronate. ${ }^{17)}$ This result was somewhat unexpected because the anti-fracture efficacy of ibandronate has been demonstrated in the spine only. ${ }^{18)}$ Given that the current evidence is based primarily on studies of weekly risedronate, two hypotheses could be assumed with regard to risedronate and ibandronate: (1) the monthly dosing has a lower efficacy than weekly dosing; or (2) risedronate has a lower efficacy than ibandronate. To test the first hypothesis, we performed the current cohort study and found that the monthly risedronate regimen was not inferior to the weekly regimen. Pharmacologically, bisphosphonates, including risedronate, have a high binding affinity to bone and risedronate is a very potent bisphosphonate. ${ }^{22)}$ These unique properties may overcome the potential lower efficacy of the long dosing interval and support our findings. For the second hypothesis, a 2-year RCT reported that monthly ibandronate was more effective than weekly risedronate on the lumbar spine and total body BMD. ${ }^{23)}$ In addition, several indirect comparative studies also noted that monthly ibandronate had better efficacy than monthly risedronate. ${ }^{14,24-26)}$ After consideration of all the evidence, monthly risedronate is not inferior to weekly risedronate and has comparable efficacy.

In addition, we should pay attention to the possible "initial" low efficacy of a long-interval dosing regimen, as seen with the monthly risedronate regimen. As mentioned above, a randomized controlled comparative study between monthly and daily risedronate for 2 years reported that the decrease in serum CTX was lower in the monthly group at 1 year (months 3,6 , and 12$){ }^{14)}$ however, there was no significant difference between treatment groups at 2 years (month 24). ${ }^{12)}$ This may be attributable to the pharmacokinetics of risedronate: the accumulating dose increases relatively slowly in the longer dosing interval than in the shorter one; however, this diminishes as the drug administration is repeated. This may raise the possibility of inferior efficacy of monthly risedronate in the initial treatment period; however, BMD and other bone turnover markers were similar throughout the treatment period. Our additional analyses performed in every follow-

B

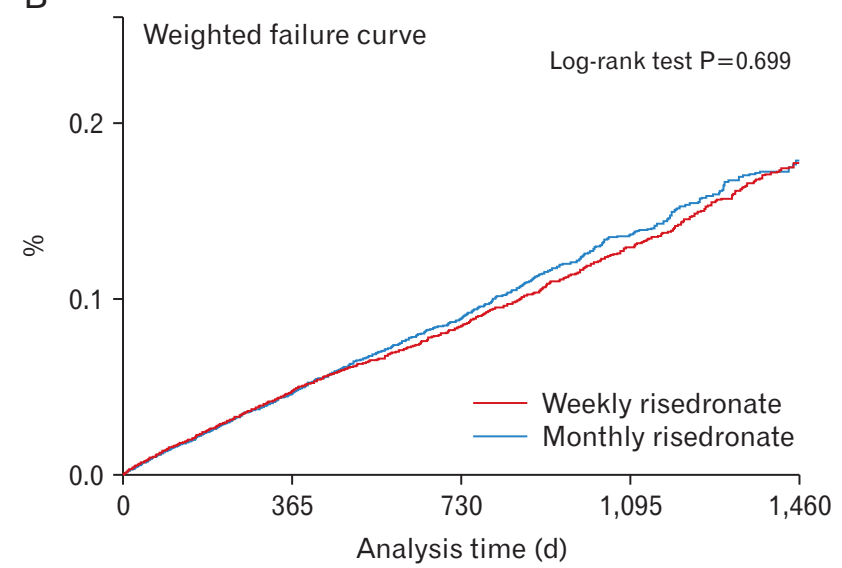

Figure 2. Kaplan-Meier curve on accumulated percentage of new osteoporotic fracture according to the treatment group. (A) Unweighted failure curve. (B) Weighted failure curve. 
up year also revealed no difference in anti-fracture efficacy (data not shown). Thus, we found that the efficacy of the monthly risedronate regimen was similar to that of the weekly regimen, regardless of treatment period. As all these epidemiologic studies have some methodological caveats, further large-scale, well-designed studies are needed for our findings.

There are some limitations in the current study. First, misclassification of the incident fracture may have been possible as the identification of fractures was reliant on diagnosis codes. However, to identify authentic osteoporotic fractures, we excluded traumatic or pathologic fracture using ICD-10 codes. Second, although we set the washout period of other bisphosphonates as 2 years, their residual effect may have persisted beyond 2 years and affected the development of fractures in the treatment groups, giving rise to between-group differences. Third, the indication of prescription, such as the severity of osteoporosis, may have been different between the treatment groups, which may have biased the results. Fourth, although we tried to balance both treatment groups by using propensity score matching and adjusting for several confounding variables, we could not include several important factors that might influence fragility fractures, such as BMD, alcohol intake, smoking status, physical exercise, body fat, and risk of falling. ${ }^{18,27-30)}$ Fifth, this comparative anti-fracture study was limited to the Korean population. Therefore, this result should be applied cautiously to Caucasians as well as other Asian populations. Sixth, medication adherence is an important factor that may affect the results. Thus, we only included those with high adherence (MPR > 80\%) and considered MPR in the Cox regression analysis. Despite this methodological consideration, MPR may have been different between treatment groups. A comparison of the mean difference of two groups or stratified analysis may provide additional information on the modified effect by MPR. However, further analysis was not possible owing to the time constraints on data access. Hence, additional studies are warranted to evaluate potential bias owing to the difference in MPR between treatment groups. Finally, safety is another issue in choosing medication. However, we did not assess the treatment-related adverse events.

Despite the aforementioned limitations, the current study has several strengths. To the best of our knowledge, this is the first study to compare the anti-fracture efficacy of monthly and weekly regimens of risedronate. In addition, this is one of the few studies that has evaluated the anti-fracture efficacy of monthly risedronate. A large-scale cohort and a relatively long follow-up duration are the other strengths of this study. Owing to the low incidence of fragility fractures, a larger cohort study, over an extended period, should provide more convincing evidence. Finally, the included cohort is nationally representative; therefore, it is advantageous to apply the results to the general Korean population.

In conclusion, we found that a monthly dose of risedronate showed similar anti-fracture efficacy to that of a weekly dose in Korean women of $\geq 50$ years of age with osteoporosis. Further, large-scale, well-designed studies are warranted to confirm our findings.

\section{CONFLICT OF INTEREST}

No potential conflict of interest relevant to this article was reported.

\section{ACKNOWLEDGMENTS}

This study was supported by Wonkwang University in 2019.

\section{ORCID}

Yong Ho Cho: https://orcid.org/0000-0002-0718-7512

Kyung Hyun Bae: https://orcid.org/0000-0003-1828-4913

Dong Ryul Lee: https://orcid.org/0000-0001-7255-4561

Jungun Lee: https://orcid.org/0000-0001-8580-1445

\section{REFERENCES}

1. Ha YC. Epidemiology of osteoporosis in Korea. J Korean Med Assoc 2016;59:836-41.

2. Park EJ, Joo IW, Jang MJ, Kim YT, Oh K, Oh HJ. Prevalence of osteoporosis in the Korean population based on Korea National Health and Nutrition Examination Survey (KNHANES), 2008-2011. Yonsei Med J 2014;55:1049-57.

3. Ha YC, Park YG, Nam KW, Kim SR. Trend in hip fracture incidence and mortality in Korea: a prospective cohort study from 2002 to 2011. J Korean Med Sci 2015;30:483-8.

4. Bliuc D, Nguyen ND, Milch VE, Nguyen TV, Eisman JA, Center JR. Mortality risk associated with low-trauma osteoporotic fracture and subsequent fracture in men and women. JAMA 2009;301:513-21.

5. Ha YC, Kim HY, Jang S, Lee YK, Kim TY. Economic burden of osteoporosis in South Korea: claim data of the National Health Insurance Service from 2008 to 2011. Calcif Tissue Int 2017;101:623-30.

6. McClung MR, Geusens P, Miller PD, Zippel H, Bensen WG, Roux C, et al. Effect of risedronate on the risk of hip fracture in elderly women. Hip Intervention Program Study Group. N Engl J Med 2001;344:33340.

7. Harris ST, Watts NB, Genant HK, McKeever CD, Hangartner T, Keller $\mathrm{M}$, et al. Effects of risedronate treatment on vertebral and nonvertebral fractures in women with postmenopausal osteoporosis: a randomized controlled trial. Vertebral Efficacy with Risedronate Therapy (VERT) Study Group. JAMA 1999;282:1344-52.

8. Ste-Marie LG, Brown JP, Beary JF, Matzkin E, Darbie LM, Burgio DE, et al. Comparison of the effects of once-monthly versus once-daily risedronate in postmenopausal osteoporosis: a phase II, 6-month, multicenter, randomized, double-blind, active-controlled, dose-ranging study. Clin Ther 2009;31:272-85.

9. Delmas PD, Benhamou CL, Man Z, Tlustochowicz W, Matzkin E, Eusebio $\mathrm{R}$, et al. Monthly dosing of $75 \mathrm{mg}$ risedronate on 2 consecutive days a month: efficacy and safety results. Osteoporos Int 2008;19:103945.

10. Racewicz AJ, Schofield PJ, Cahall DL, Cline GA, Burgio DE. Monthly dosing with risedronate $50 \mathrm{mg}$ on three consecutive days a month compared with daily dosing with risedronate $5 \mathrm{mg}$ : a 6 -month pilot 
study. Curr Med Res Opin 2007;23:3079-89.

11. Brown JP, Kendler DL, McClung MR, Emkey RD, Adachi JD, Bolognese MA, et al. The efficacy and tolerability of risedronate once a week for the treatment of postmenopausal osteoporosis. Calcif Tissue Int 2002; 71:103-11.

12. McClung MR, Zanchetta JR, Racewicz A, Roux C, Benhamou CL, Man $\mathrm{Z}$, et al. Efficacy and safety of risedronate 150-mg once a month in the treatment of postmenopausal osteoporosis: 2-year data. Osteoporos Int 2013;24:293-9.

13. McClung MR, Balske A, Burgio DE, Wenderoth D, Recker RR. Treatment of postmenopausal osteoporosis with delayed-release risedronate $35 \mathrm{mg}$ weekly for 2 years. Osteoporos Int 2013;24:301-10.

14. Delmas PD, McClung MR, Zanchetta JR, Racewicz A, Roux C, Benhamou CL, et al. Efficacy and safety of risedronate $150 \mathrm{mg}$ once a month in the treatment of postmenopausal osteoporosis. Bone 2008; 42:36-42.

15. Soen S, Umemura T, Ando T, Kamisaki T, Nishikawa M, Muraoka R, et al. Efficacy on the risk of vertebral fracture with administration of once-weekly $17.5 \mathrm{mg}$ risedronate in Japanese patients of established osteoporosis with prevalent vertebral fractures: a 156-week longitudinal observational study in daily practice. J Bone Miner Metab 2017;35: 419-27.

16. Bonnick S, Saag KG, Kiel DP, McClung M, Hochberg M, Burnett SM, et al. Comparison of weekly treatment of postmenopausal osteoporosis with alendronate versus risedronate over two years. J Clin Endocrinol Metab 2006;91:2631-7.

17. Lee DR, Lee J. Comparison of the efficacy between once-monthly oral ibandronate and risedronate among Korean women with osteoporosis: a nationwide population-based study. Osteoporos Int 2019;30:65966.

18. Camacho PM, Petak SM, Binkley N, Clarke BL, Harris ST, Hurley DL, et al. American Association of Clinical Endocrinologists and American College of Endocrinology clinical practice guidelines for the diagnosis and treatment of postmenopausal osteoporosis: 2016. Endocr Pract 2016;22(Suppl 4):1-42.

19. Siris ES, Selby PL, Saag KG, Borgstrom F, Herings RM, Silverman SL. Impact of osteoporosis treatment adherence on fracture rates in North America and Europe. Am J Med 2009;122(2 Suppl):S3-13.
20. Recommendations for the prevention and treatment of glucocorticoid-induced osteoporosis: 2001 update. American College of Rheumatology Ad Hoc Committee on Glucocorticoid-Induced Osteoporosis. Arthritis Rheum 2001;44:1496-503.

21. Austin PC. Using the standardized difference to compare the prevalence of a binary variable between two groups in observational research. Commun Stat Simul Comput 2009;38:1228-34.

22. Nancollas GH, Tang R, Phipps RJ, Henneman Z, Gulde S, Wu W, et al. Novel insights into actions of bisphosphonates on bone: differences in interactions with hydroxyapatite. Bone 2006;38:617-27.

23. Paggiosi MA, Peel N, McCloskey E, Walsh JS, Eastell R. Comparison of the effects of three oral bisphosphonate therapies on the peripheral skeleton in postmenopausal osteoporosis: the TRIO study. Osteoporos Int 2014;25:2729-41.

24. Nakamura T, Nakano T, Ito M, Hagino H, Hashimoto J, Tobinai M, et al. Clinical efficacy on fracture risk and safety of $0.5 \mathrm{mg}$ or $1 \mathrm{mg} / \mathrm{month}$ intravenous ibandronate versus $2.5 \mathrm{mg}$ /day oral risedronate in patients with primary osteoporosis. Calcif Tissue Int 2013;93:137-46.

25. Nakamura T, Ito M, Hashimoto J, Shinomiya K, Asao Y, Katsumata K, et al. Clinical efficacy and safety of monthly oral ibandronate $100 \mathrm{mg}$ versus monthly intravenous ibandronate $1 \mathrm{mg}$ in Japanese patients with primary osteoporosis. Osteoporos Int 2015;26:2685-93.

26. Nakai K, Tobinai M, Hashimoto J, Iida S, Kawanishi T. The optimal oral dose selection of ibandronate in Japanese patients with osteoporosis based on pharmacokinetic and pharmacodynamic properties. Eur J Drug Metab Pharmacokinet 2016;41:139-47.

27. Yang YJ. An overview of current physical activity recommendations in primary care. Korean J Fam Med 2019;40:135-42.

28. Park SM, Ryu J, Lee DR, Shin D, Yun JM, Lee J. Zolpidem use and risk of fractures: a systematic review and meta-analysis. Osteoporos Int 2016;27:2935-44.

29. Kim DH, Lim H, Chang S, Kim JN, Roh YK, Choi MK. Association between body fat and bone mineral density in normal-weight middleaged Koreans. Korean J Fam Med 2019;40:100-5.

30. Kim J, Kwon H, Heo BK, Joh HK, Lee CM, Hwang SS, et al. The association between fat mass, lean mass and bone mineral density in premenopausal women in Korea: a cross-sectional study. Korean J Fam Med 2018;39:74-84. 